\title{
Desmediatização, infodemia e fake news na cultura digital
}

\author{
Débora Liberato Arruda Hissa*
}

\section{Resumo}

Neste artigo, discuto o fenômeno da desmediatização (HAN, 2018) e sua relação direta com pandemia de informação (infodemia) e a antiquíssima prática social, com base política e econômica, de divulgação de notícias falsas (modernamente conhecidas como fake news) como consequência da vulgarização de opiniões disruptivas propagadas pela cultura digital. Com base na abordagem antagonística de Mouffe (2015) - que reconhece a inerradicabilidade da dimensão conflituosa da vida social, proponho olhar a disseminação de fake news, tanto na mídia como nas redes sociais, a partir de uma dimensão ideológica de forças pulsionais que mobiliza paixões e crenças; cria mitos e fantasias apoiada em uma moralidade forjada na narrativa antitética do "nós/eles". Para isso, analiso dois contextos enunciativos distintos: o primeiro se refere à divulgação pela mídia, em 2011, primeiro ano de mandato de Dilma Rousseff (PT), da notícia de que o MEC chancelou a distribuição de material didático que defende e estimula erros de concordância verbal no ensino de Língua Portuguesa; o segundo, dez anos depois, em 2021, na gestão de Jair Bolsonaro (sem partido), a notícia da proposta de reforma eleitoral, apresentada pela Câmara dos Deputados, que dificulta as plataformas digitais de punirem candidatos que divulguem fake news nas eleições de 2022. Tais eventos explicam como narrativas desmediatizadas sustentam e recriam o antagonismo

* Universidade Estadual do Ceará (UECE). Doutora em Linguística Aplicada. Professora do Programa de Pós-graduação em Linguística Aplicada (POSLA/UECE). https://orcid.org/0000-0001-6075-5585. 
estrutural como ponto fundante das sociedades modernas e se potencializam na cultural digital.

Palavras-chave: Infodemia. Fake News. Desmediatização. Agonística. Cultura Digital.

\section{Demediatization, Infodemia and Fake News in Digital Culture}

\section{Abstract}

In this article, I discuss the phenomenon of demediatization (HAN, 2017; 2018) and its direct relationship with the information pandemic (Infodemia) and the age-old social practice, with a political and economic basis, of disseminating false news (modernly known as fake news) as a consequence of the popularization of disruptive opinions propagated by digital culture. Based on Mouffe (2015) antagonistic approach - which recognizes the ineradicability of the conflicting dimension of social life, I propose to look at the spread of fake news, both in the media and on social networks, from an ideological dimension of drive forces that mobilizes passions and beliefs; creates myths and fantasies supported by a morality forged in the antithetical narrative of we/them. For this, I analyze two distinct enunciative contexts: the first refers to the disclosure by the media, in 2011, the first year of Dilma Rousseff (PT) term, of the news that the MEC approved the distribution of teaching material that defends and encourages mistakes in verbal agreement in Portuguese language teaching; the second, ten years later, in 2021, in the administration of Jair Bolsonaro (no party), the news of the electoral reform proposal, presented by the Chamber of Deputies, which makes it difficult for digital platforms to punish candidates who disseminate fake news in the 2022 elections Such events explain how demediatized narratives sustain and recreate the structural antagonism as 
the foundation point of modern societies and are leveraged in digital culture.

Keywords: Infodemic. Fake News. Demediatization. Agonistic. Digital Culture.

Recebido em: 06/07/2021 // Aceito em: 04/10/2021. 


\section{Imaginário, simbólico e realidade: representação e linguagem}

Somos seres de linguagem. Somos seres humanos na e pela linguagem. Evoluímos como espécie em função de nossa condição idiossincrática biopsicossocial de representar e criar significados por meio da linguagem. A linguagem funda nossa inscrição no simbólico, no imaginário, na fantasia e, por nossa condição estrutural humana de impossibilidade de uma simbolização referencial absoluta, a linguagem nunca captura o real. A realidade vivida pode ser apenas enunciada por verossimilhança com aquilo que o ser humano percebe por meio dos seus sentidos. Por conta dessa limitação estrutural, nunca apreendamos ou enunciamos o real. Eis a beleza alegórica dos seres de linguagem: construímos sentido de modo incrivelmente versátil e multifacetado, porém cada construção enunciativa apresenta apenas possibilidades de representar a realidade, os fatos, os acontecimentos. E é exatamente nessa tentativa de simbolizar a realidade pela linguagem que nos subjetivamos ideologicamente como seres sociais.

Essa discussão sobre o real, o simbólico e o imaginário me parece interessante para este início de conversa. Antes de discutir sobre os temas-chave deste artigo, desmediatização e fake news, pretendo problematizar, com base nos preceitos da psicanálise lacaniana, o que entendemos como realidade. Escolho esse percurso argumentativo inicial para dizer muito claramente que a realidade é uma construção simbólica imaginada, experimentada e enunciada pela linguagem, cujas inferências para a compreensão só se dão em função de uma interação social concreta. Cada realidade construída pela linguagem é 
atravessava pelo Zeitgeist de sua época, pela cultura, política e economia. Assim, temos, tanto num mesmo período histórico como em períodos diferentes, sempre realidades no plural. É justamente o argumento de realidades no plural que me interessa por enquanto.

Lacan (2005) explica que o real é diferente do simbólico e do imaginário. O real escapa à simbolização, enquanto o simbólico estrutura a realidade humana. Isso quer dizer, segundo Lacan, que nós, seres humanos, só temos acesso à realidade à medida que, além do imaginário, das significações, fazemos uso do simbólico, do significante. ${ }^{1}$

Lendo linguisticamente, o imaginário seria uma espécie de alienação a uma compreensão absoluta do enunciado. ${ }^{2}$ A ideia de compreensão absoluta repercute no modo como lidamos com nossas interações com a linguagem, sobretudo com a modalidade escrita. Para o imaginário, há uma relação direta entre a palavra (imagem) e o seu significado, pois ele se aliena a uma possibilidade de reciprocidade absoluta de compreensão entre o eu-outro. Quem rompe essa alienação entre imagemsignificado advinda do imaginário é o simbólico. Ele é um sistema representativo social, um conjunto de posições enunciativas que circunscreve e representa lugares, tempos, espaços, mitos, crenças, valores, posições identitárias e ideologias. ${ }^{3} \mathrm{O}$ simbólico não tem significado em si mesmo, pois ele só pode ser inferido/

1 Lacan define o significante com base na Antropologia de Lévi-Strauss e na Linguística de Saussure, especificamente o Curso de Linguística Geral (1916).

2 O enunciado, neste texto, é compreendido como a real unidade de comunicação discursiva, não abstrata. Trata-se não de uma unidade convencional, mas sim de uma unidade real, viva - unidade autêntica da comunicação discursiva - precisamente delimitada pela alternância de sujeitos do discurso. Ele é que determina a ativa posição responsiva dos outros participantes da comunicação (BAKHTIN, 2011)

3 A noção de ideologia, neste artigo, tem como base o conceito de ideologia de Marx e Engels (2007). Os autores, ao explicarem o termo, buscam a relação entre o âmbito "ideal" da ideia, dos valores, juízos e representações - que correspondem a uma consciência social de uma dada época - e a sociedade na qual tal relação está inserida. Para Marx e Engels, as ideias hegemônicas são as da classe dominante, ou seja, elas refletem apenas a expressão ideal das relações que fazem de uma classe a classe dominante. 
compreendido a partir das relações que um elemento (simbólico) tem com outro conjunto de elementos (também simbólicos). Assim, podemos dizer que a realidade que enunciamos é composta pelo simbólico e pelo imaginário; logo, tal como a enunciamos, ela não nos é apresentada como uma totalidade integrada, harmoniosa, dotada de sentido pleno, e sim como uma representação simbólica social atravessada por ideologias (imaginário). Esse é um ponto importante para a nossa discussão sobre desmediatização, infodemia e fake news na cultura digital.

Socialmente, conhecemos várias formas simbólicas, como os mitos (narrativas fantasiosas, lendas, tabus, crenças); as narrativas político-econômicas (os discursos raciais, as guerras por território, o processo genocida da colonização, as cruzadas de verniz religioso, a caça às bruxas); as relações de gênero (sexuação, ${ }^{4}$ misoginia, homofobia, transfobia), etc. Muitas dessas formas simbólicas de enunciar uma realidade foram "ditadas" por aqueles que detinham o controle político e econômico social para exercer o direito de representar enunciativamente uma realidade por meio da linguagem. Arrisco dizer que nenhuma dessas representações tem uma base cartesiana de verdade, de método científico e que todas foram (e continuam sendo) narrativas falsas. Isso significa que representar uma realidade para determinado fim está na base de nossa organização como seres humanos "civilizados", mesmo que para isso fosse necessário falseá-la.

\footnotetext{
4 Conferir esta discussão sobre sexuação em Lacan (1998).

5 Yuval Harari, em seu best-seller Sapiens (2017), explica que uma das hipóteses para a evolução cognitiva da linguagem foi a necessidade de o Homo sapiens fazer fofoca. Como animal social, a cooperação era essencial para a sobrevivência e reprodução; assim, era muito importante para o bando saber em quem se podia confiar, quem era trapaceiro, honesto, preguiçoso, atencioso, etc.
} 
Histórias inventadas sobre os povos originários, ${ }^{6}$ sobre o Continente Africano, sobre o Oriente, sobre a civilidade iluminista europeia, ${ }^{7}$ sobre o patriarcado - todas criadas abusiva e criminosamente com a única finalidade de exterminar, colonizar, torturar, aprisionar e silenciar maiorias que não exerciam o poder outorgado a uma minoria - sempre existiram e causam mortes, assassinatos e violências simbólicas até hoje. Sendo assim, por que o fenômeno contemporâneo das fake news nos causa tanta aflição, preocupação e ojeriza, já que estamos lidando com a base enunciativa de toda sociedade (a representação simbólica da realidade ideologizada)? Por que notícias falsas emergentes e contingenciais, replicadas milhares de vezes nas mídias digitais, nos impactam mais do que a propagação de crenças moralizantes, de mitos religiosos, de leis arbitrárias e de conteúdos racistas igualmente falsos e sem nenhuma base científica ou empírica? Por que contemporizamos o conteúdo perverso de algumas representações simbólicas e execramos o continente sedimentado e contingencial de outras?

Nas próximas seções deste artigo, pretendo elucidar melhor essas considerações. Primeiramente, tomo como base para reflexão sobre fake news a dimensão antagonística constitutiva do político, descrita por Chantal Mouffe (2015), para, em seguida, propor uma discussão sobre os fenômenos contemporâneos da infodemia ${ }^{8}$ a partir da concepção de desmediatização na sociedade do desempenho (HAN, 2017a, 2018) como principal fator para a disseminação de notícias falsas na cultura digital.

6 A carta de Pero Vaz de Caminha (escrivão da frota de Pedro Álvares Cabral), escrita em $1^{\circ}$ de maio de 1500 ao rei Manuel I, foi, talvez, a primeira narrativa fantasiosa de que temos notícia em solo brasileiro. Seria a primeira fake news da história do Brasil?

7 Sobre essa discussão, sugiro conferir a obra Crítica da Razão Pura (KANT, 2001) e a reflexão sobre o espírito absoluto no livro Fenomenologia do Espírito (HEGEL, 2002).

8 Imediatamente após a covid-19 ser declarada uma Emergência de Saúde Pública de preocupação internacional, a equipe de comunicação da Organização Mundial de Saúde (OMS) lançou uma nova plataforma de informação chamada EPI-WIN: WHO Information Network for Epidemics (https://www.who.int/teams/risk-communication). Essa plataforma teve como objetivo compartilhar informações seguras e precisas sobre a covid-19 e assim combater o risco de uma infodemia (https://www.who.int/ teams/risk-communication/infodemic-management), ou seja, uma pandemia de informações falsas sobre a doença que, como sabemos, causou enormes danos a várias pessoas no Brasil e no mundo. (Cf. ZAROCOSTAS, 2020). 


\section{Fake news e a dimensão antagonística: consequência e causa}

Para abrir a discussão sobre a dimensão antagonística da política defendida por Mouffe (2015) e relacioná-la com a prática de criação e divulgação de fake news, parto da noção, com base nessa autora, de que toda sociedade é o resultado de um conjunto de atividades enunciativas que tentam estabelecer ordem em um contexto de múltiplas contingências locais e globais. ${ }^{9}$ Esse conjunto de práticas sociointerativas se dá a partir de uma organização político-hegemônica que articula suas demandas econômicas por meio de formas específicas de representação social, sem, contudo, levar em conta qualquer racionalidade a priori. Tal organização se identifica com atividades de instituições cuja soberania é estabelecida socialmente (e sem muita contestação da maioria excluída). Por meio dessas instituições, narrativas "oficiais" são criadas, muitas vezes por sujeitos que têm posição de autoridade em determinadas entidades (na religião, na aristocracia, na burguesia, na política, na mídia, na ciência ou na academia). Essas narrativas oficiais garantem a tais enunciados valor de verdade.

Pelo fenômeno da desmediatização ${ }^{10}$ (HAN, 2018), as narrativas oficiais sofreram um processo de sedimentação cujas representações simbólicas se deram em diferentes esferas sociais (religião, educação, justiça, ciência, entretenimento). Narrativas sedimentadas são parte constitutiva de qualquer sociedade e elas se articulam de forma temporária às práticas políticas contingentes. Esse processo se baseia em alguma forma de exclusão, pois cada

\footnotetext{
9 Foucault (2015) promove uma rica discussão sobre as relações de poder à luz das táticas, dos conflitos, das lutas entre aqueles que o exercem (indivíduos ou grupos) e aqueles que tentam escapar, contestando-o ou enfrentando-o, de modo global ou local. 10 Discutiremos esse processo de forma mais detalhada na quarta seção deste artigo.
} 
contexto enunciativo exclui possibilidades de narrativas, as quais, embora reprimidas, permanecem latentes e podem ser reativadas a qualquer momento. O principal elemento para a sedimentação das narrativas é a formulação identitária da oposição "nós/eles". Essa formulação implica o estabelecimento de uma diferença que muitas vezes se constrói com base numa hierarquia: forma e conteúdo, preto e branco, homem e mulher, etc. (MOUFFE, 2015). As fake news são formadas justamente com base nesse contexto de sedimentação das narrativas e formulação identitária de oposição "nós/eles", uma vez que fazem parte de um conjunto de práticas que organizam a coexistência humana no contexto conflituoso produzido pelas relações políticas.

Mouffe (2015) produz toda uma reflexão sobre a dimensão agonística irremediável do político, na qual afirma que a política democrática deve colocar o poder e o antagonismo no centro de sua concepção. Com base nessa autora, procuro argumentar a favor da irredutibilidade da criação e divulgação de notícias falsas na esfera política, uma vez que tanto a estrutura da política tem como base a dicotomia amigo/inimigo, ${ }^{11}$ como as formas de exclusão "eles sim/eles não" organizam toda ordem política. A dicotomia amigo/inimigo está sempre relacionada a formas coletivas de identificação, de tal modo que estamos sempre lidando com a criação de um "nós" que só pode existir pela demarcação de um "eles” (MOUFFE, 2015), com base em uma exterioridade constitutiva.

A dicotomia "nós/eles" é a alienação ideal para justificar a divulgação de fake news como enunciados políticos emergenciais - em alusão a um fato pontual específico, por exemplo -, porque criamos a ficção, pelo viés do imaginário, de que o "eles" ameaça

11 Para elaborar sua reflexão crítica sobre Pluralismo e relação amigo/inimigo, Chantal Mouffe (2015) parte das premissas de grupamentos amigos/inimigos, de Carl Schmitt; e de exterioridade constitutiva, de Henry Staten. 
a existência do "nós". Demarcamos fronteiras ideológicas simbólicas para justificar o constante estado de ameaça em que nos encontramos e saímos como franco-atiradores em nome da extinção do "inimigo". Trata-se de uma luta pela manutenção da hegemonia e da soberania nas relações de poder, custe o que custar. Por isso, para entendermos as motivações que levam à massiva divulgação das fake news nas redes sociais contemporâneas, é antes necessário reconhecermos que a distinção "nós/eles" é condição básica para a formação das identidades políticas em espaços de antagonismos estruturais.

Para Mouffe, é ilusão acreditar no advento de uma sociedade em que o antagonismo possa ser erradicado, uma vez que "toda antítese religiosa, moral, econômica, ética ou outra transformase numa antítese política se for suficientemente forte para reunir eficazmente os seres humanos em grupo de amigos e inimigos [...]" (MOUFFE, 2015, p. 11). ${ }^{12}$ Por isso, nas sociedades democráticas, a ausência de uma fonte superior de lei, poder ou conhecimento coloca o legítimo e o ilegítimo em constante contestação, de modo que eles nunca podem ser definidos de forma absoluta.

Dessa forma, narrativas sedimentadas sempre são rediscutidas, questionadas, debatidas, pois não se fundamentam mais em nenhuma verdade irredutível. Por isso é importante termos em mente que, no reino da política-assim como aludimos em nossa explicação sobre o imaginário, simbólico e real - não prevalece a verdade (ou a realidade), uma vez que cada esfera ideológica possui critérios de validação e legitimação para além do racional e do verídico. Na esfera política contemporânea, advinda da cultura digital, parece não haver mais espaço para verdades universais - se é que elas existem.

12 Mouffe faz essa reflexão com base em Schmitt (1976). 
A antítese política se apossou dos meios de comunicação em massa de modo a potencializar a dimensão antagonística do "nós/eles". Com a criação da rádio, dos jornais, da televisão e, sobretudo, das mídias digitais, as fronteiras entre o social e o político ficaram cada vez mais instáveis e, consequentemente, surgiu a necessidade de constante negociação entre os agentes sociais para garantir que a sua realidade hegemônica se sobrepusesse às demais. Foi assim que, em um determinado momento da história, muito do que foi considerado "natural" (o monarca como representante de Deus na Terra; a compra e venda de pessoas como escravas; a condenação de mulheres como bruxas; o sol circunscrevendo a Terra; os povos originários como bárbaros sanguinários; os negros como seres inferiores) sofreu o processo de sedimentação contra-hegemônico que buscou desarticular a ordem existente e instalar outra forma de hegemonia.

As fake news igualmente tentam promover a desarticulação de uma ordem hegemônica (aqui representada pela ciência, pela academia, pelo empirismo) a partir de narrativas criadas para estimular conflitos passionais, moralistas que, fincados na dimensão afetiva, relegam a dimensão racional/científica para um terceiro ou quarto plano. Para Perez (2018, p. 177), essa dimensão afetiva precisa ser relacionada à diferença entre massa e povo no que se refere à lógica das identificações coletivas. A identidade de povo se dá a partir da lógica das demandas, porém a identidade da massa se constrói pelo vínculo libidinal com o líder. Perez é categórico ao dizer que a massa atualmente tem um líder: a grande mídia. Ela tem como tarefa instalar e reinstalar afetividade e oferecer alguém a quem odiar. Para a massa, o vínculo libidinal com o líder permite o reconhecimento do outro 
semelhante (outro “nós”) e juntos eles compõem um grupo (nosso "nós"). Como amontoado de indivíduos, a massa é afetada pelo líder - aqui identificado como a mídia que cria laços verticais de relação - que busca estrategicamente, segundo Perez (2018), provocar sentimentos de ódio e depreciação, objetivando romper com os laços sociais. A ideia de a massa identificar a mídia como líder se articula ao processo de manipulação de notícias falsas destinadas a um coletivo de indivíduos, cujo vínculo interno se dá por semelhança ideológica de grupo.

Ainda com base em Perez, pode-se dizer que a linguagem empregada nas notícias falsas é instrumentalizada pela mídia para provocar estados afetivos e pulsionais. Isso significa que a mídia, como líder, constrói modos de enunciação que lidam com dimensões pulsionais da massa, e eles ganham valor de verdade para aquele grupo de indivíduos.

Nessa posição meramente imaginária da linguagem, a verdade é substituída pela adesão a um enunciado ou discurso que não precisa ser nem razoável nem verossímil, mas que permite almejar imaginariamente um gozo perverso (em relação a um outro, tomado como objeto a ser descartado) e/ ou uma promessa de gozo, um usufruto privilegiado porque, como indivíduo meritocrático, competitivo, empreendedor esforçado, inteligente e astuto numa sociedade onde cada um busca sua sobrevivência e o sucesso pessoal, já foram cortados os laços com a comunidade, apenas resta a realização individual ou no máximo em relação com os próprios sócios (PEREZ, 2018, p. 185, grifo nosso).

Ao cortar os laços com a comunidade em função apenas de uma realização individual (ou com os pares), como pontuou Perez, tem-se o fetichismo do poder, no qual o ator político (os membros da comunidade política, sejam cidadãos ou 
representantes) acredita poder afirmar sua própria subjetividade para a instituição em que cumpre alguma função - executiva, legislativa ou judiciária - como a sede ou a fonte do poder político (DUSSEL, 2007, p. 14). O líder, então, seria uma autoridade autorreferente que mantém a dinâmica do antagonismo com base na estratégia discursiva de divulgação de fake news.

\section{Fake news na mídia e a adesão da massa}

A afirmação de que a verdade é substituída por uma adesão a um enunciado ou discurso do líder, que não precisa ser nem razoável nem verossímil, me parece ser o cerne da aceitação e da divulgação das fake news. Para exemplificar tudo o que venho discutindo até aqui, trago como exemplo um caso de uma polêmica forjada pela mídia em 2011, que muito elucida a relação entre a dimensão antagonística da política, a construção identitária do coletivo de massa "nós/eles", e o vínculo libidinal da massa com a mídia. Estou me referindo ao caso de um livro didático, chamado Por uma vida melhor, da coleção Viver, Aprender (editora Global), destinado a alunos da Educação de Jovens e Adultos (EJA) e distribuído pelo MEC para 4.236 escolas. O livro foi publicado no primeiro ano de mandato de Dilma Rousseff (PT), cujo Ministro da Educação era Fernando Haddad.

Houve uma massiva divulgação pela mídia de notícias falsas ligadas a esse livro, e a sociedade em geral aderiu à narrativa agonística enunciada pelo líder sem a menor contestação sobre sua legitimidade ou veracidade. Vamos aos fatos: 1) o livro é destinado para alunos da EJA; 2) o livro, apenas no capítulo intitulado "Escrever é diferente de falar", traz, em um trecho 
específico, as diferenças entre as variantes vernaculares, que os alunos da EJA aprenderam antes de entrar na escola, e a variante culta exigida em alguns espaços sociais de prestígio; 3) a linguagem formal e a variante culta são a base textual de todo o livro; 4) o livro não contém desvios gramaticais e, quando as autoras os textualizaram de forma consciente e proposital, $\mathrm{o}$ fizeram unicamente no capítulo supracitado, para mostrar que esses modos de uso da língua existem. Vamos às notícias falsas divulgadas na mídia: 1) o livro é destinado a alunos do ensino básico; 2) o livro ensina os alunos a falarem e a escreverem errado; 3) o livro despreza a variante culta; 4) o livro contém uma série de erros gramaticais.

Parece-me claro que aqueles que geraram essa polêmica não estavam interessados na qualidade do ensino de Língua Portuguesa, mas, sim, em deslegitimar as pretensões políticas (distribuição de material didático) do seu oponente, como acontece na relação antagonística amigo/inimigo. Há marcadamente uma oposição política entre o nós, representado pelas classes conservadoras e os partidos de direita, e o eles, representados pelas classes progressistas e os partidos de esquerda, então no poder. Temos, assim, um caso clássico de fake news divulgado pela mídia, ainda que não tenha ganhado socialmente uma repercussão como tal. A seguir, trago alguns exemplos de notícias falsas divulgadas pelos principais canais de mídia do Brasil: a revista Veja, o jornal Estadão, o site Globo. com, e o telejornal Bom dia, Brasil, envolvendo a distribuição do livro Por uma vida melhor para os alunos da EJA.

Com a manchete "As lições do livro que desensina" a revista Veja (GOULART, 2011), publicada em 20 maio de 2011, afirma que o livro Por Uma Vida Melhor é um "exemplo de 
doutrina difundida há décadas na educação brasileira, segundo a qual a norma culta é um fardo ao qual devemos nos curvar por imposição social, e não pelos benefícios que ela propicia”. Notese que temos um exemplo reiterado de contestação identitária antagonística que marca o "eles" como aqueles que doutrinam por imposição social, e o "nós" como aqueles que veem os benefícios do ensino na norma culta. Aqui, o líder seria a Veja, que oferece à massa quem odiar: os doutrinadores petistas. Arena ideológica formada; "pancadas" de fake news à vista.

Outro exemplo de matéria que forja uma polêmica sobre esse livro foi escrito no jornal O Estado de São Paulo (SADENBERG, 2011). Com o título "Se pelo menos ensinassem Português", o texto, assinado pelo jornalista Carlos Alberto Sadenberg, assevera que, nas escolas brasileiras, não se ensina o português oficial, como afirmam "professores e linguistas alinhados na tese de que não há o certo e o errado no uso da língua. Há apenas o adequado e o inadequado. Assim, 'nós pega o peixe’ não está errado. E se disser que é, sim, errado, estará cometendo 'preconceito linguístico"'. Sadenberg lança a isca ideológica para a base (a massa), quando diz que o livro Por uma vida melhor foi adotado, comprado e distribuído pelo MEC a milhares de alunos. Escreve, estrategicamente, milhares de alunos, sem definir que esses alunos são jovens e adultos do EJA. O jornalista opta conscientemente por suprir tal informação, a fim de provocar sentimentos de ódio e revolta na massa. Novamente temos um caso de fake news como estrutura da dimensão antagonística.

O maior falseamento de dessa notícia ficou por conta do jornalista e comentarista da rede Globo, na época, Alexandre Garcia. Em seu quadro de comentário sobre as notícias do dia no 
jornal Bom dia, Brasil (rede Globo), Garcia fez a seguinte fala: "se fosse apenas uma polêmica linguística, tudo bem, mas faz parte de currículo de meio milhão de alunos e é abonado pelo Ministério da Educação". ${ }^{13}$ Note-se, mais uma vez, a ênfase na notícia falsa de que o livro faz parte do currículo de meio milhão de alunos, como estratégia político-discursiva de mobilizar e inflar a massa contra o inimigo. Garcia se coaduna com o líder, a mídia, marcando sua posição de legitimidade, uma vez que atua como um porta-voz do líder.

Em julho de 2011, o site Globo.com (PROCESSO, 2011) exibiu uma matéria sobre o arquivamento do processo do recolhimento do livro Por uma vida melhor, com a seguinte manchete: "Processo contra livro do MEC com erros de concordância é arquivado. Procurador diz que obra "propõe a reflexão acerca da linguística". Polêmica sobre "nós pega o peixe" levou ministro a prestar esclarecimentos." (grifo meu). Vê-se que, mesmo depois do arquivamento do processo, as notícias falsas se mantêm. Isso acontece porque a dimensão antagonística estrutural do político se mantém no dissenso, no conflito, no falseamento da palavra do "inimigo". Como bem lembra Dussel (2007), os grupos hegemônicos usam de expressões simbólicas, imaginárias, para manobrar interesses e conservar hierarquia de poder.

O curioso é que narrativas sedimentadas contrahegemônicas não ganharam o mesmo espaço na mídia ou sequer conseguiram furar a bolha ideológica da massa para acessála. Elas circunscreveram apenas os seus próprios grupos de afinidade e, assim, ficaram fora do campo de batalha ideológico legitimado pela classe detentora dos meios de comunicação. Por

13 Fala transcrita de um vídeo postado no YouTube que traz Alexandre Garcia, no telejornal Bom dia, Brasil, comentando sobre a decisão do MEC de não recolher o livro didático Por uma vida melhor (POR UMA VIDA, 2011, grifo meu). 
exemplo, em junho de 2011, apenas um mês depois do início do bombardeio de notícias falsas pela mídia, o MEC organizou um dossiê $\hat{e}^{14}$ com mais de 15 artigos (escrito por linguísticas, professores, advogados, jornalistas, gramáticos, escritores e representantes das duas maiores associações de Linguística do Brasil - Abralin ${ }^{15}$ e $\mathrm{Alab}^{16}$ ), que saíram em sites de revistas, jornais, portais de notícias, site institucionais e blogs, com o objetivo de descaracterizar a falsa polêmica (advinda de notícias falsas) gerada em torno do livro Por uma vida melhor.

\section{Imagem 1 - Notas de repúdio das presidentes da Abralin e Alab sobre o caso envolvendo o livro didático Por uma vida melhor}

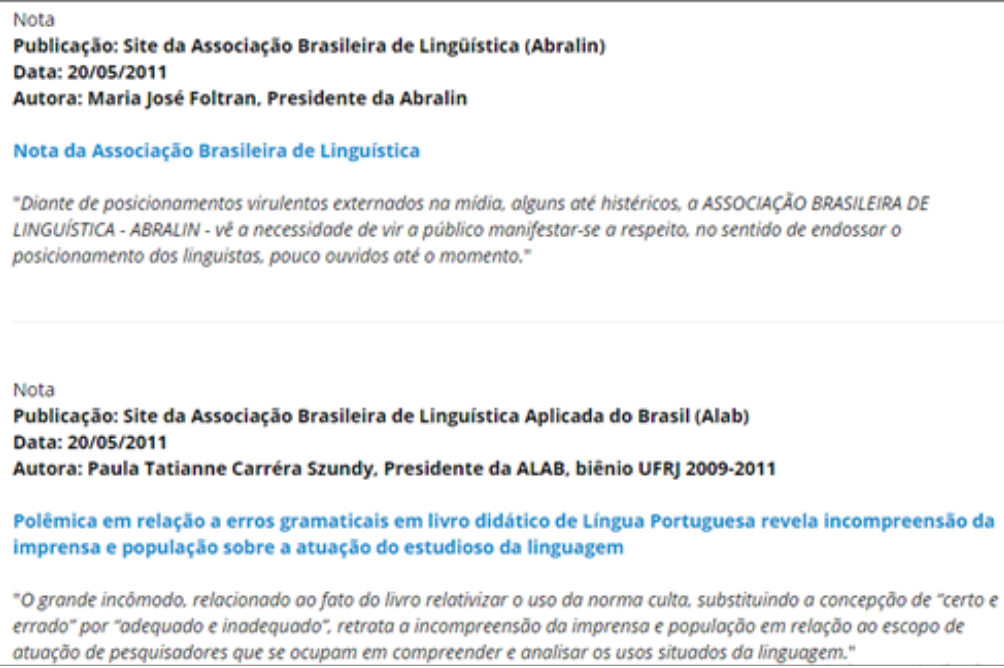

Fonte: Portal do MEC

Tal dossiê, elaborado com texto de linguistas renomados, aqueles que de fato são cientistas da linguagem, não foi

\footnotetext{
14 Disponível em: http://portal.mec.gov.br/index.php?option=com_content\&view=article\&id=16649. Acesso em: 10 jun. 2021.

15 Associação Brasileira de Linguística.

16 Associação de Linguística Aplicada do Brasil.
} 
suficiente para ganhar valor de verdade. Foucault (2008) explica que a luta pela/na linguagem se organiza a partir daquilo que chamou de economia política da verdade. Tal economia, segundo o filósofo, "é produzida e transmitida sobre controle, não exclusivo, mas dominante, de alguns grandes aparelhos políticos ou econômicos (universidade, exército, escritura, meios de comunicação); enfim, é o objeto de debate político e de confronto social (as lutas ideológicas) [...]" (FOUCAULT, 2008, p. 13). Diante desses fatos, vê-se que a massa se aliena a uma narrativa fetichizada (falsa), produto da classe dominante, com base numa identificação ideológica de pertencimento a uma classe hegemônica.

Neste momento da argumentação sobre fake news, a pergunta que se interpõem seria esta: por que não chamamos (ou não foram chamadas) de fake news as notícias falsas divulgadas pela grande mídia de massa? Por que legitimamos sem muito consternamento e alvoroço os enunciados proferidos por certos grupos da mídia? Qual é nossa posição identitária na agonística do "nós/eles"? A quem concedemos o salvo-conduto de sedimentar/forjar narrativas ideológico-políticas de "verdade"? A ideia de "o inferno são os outros" de Sartre bate-nos à porta e escancara a nossa parcialidade em torno da bandeira democrática de uma política do consenso e da racionalidade que tentamos imprimir quando nos deparamos com certas fake news. Elas são, portanto, uma forma de manutenção do conflito entre "nós/eles" que garantem a estabilidade identitária do grupo, configurando-o como unidade unívoca somente possível pela dicotomia "amigo/ inimigo". Fake news criam contorno de identidades na massa. Esse é o ponto. 


\section{Desmediatização, infodemia e fake news: causa e consequência}

Começo esta seção com a definição de infodemia elaborada de forma colaborativa pela Organização Mundial de Saúde(OMS) e pela Organização Pan-americana de Saúde (OPAS): "infodemia é um excesso de informações, algumas precisas e outras não, que tornam difícil encontrar fontes idôneas e orientações confiáveis quando se precisa [...]" (ORGANIZAÇÃO PAN-AMERICANA DA SAÚDE, 2020). Esse excesso de informação se dá em um contexto de desmediatização próprio da cultura digital, processo responsável pela vulgarização das fake news.

Para Han (2018), a comunicação digital se caracteriza pelo fato de que as informações contemporaneamente são produzidas, enviadas e recebidas sem intermediários - como as mídias tradicionais, por exemplo -, o que caracteriza o movimento de desmediatização. Logo, redes socias como Instagram, Twitter ou Facebook desmediatizam a comunicação antes dominada quase que exclusivamente por alguns veículos legitimados socialmente e que definiam a ordem do discurso (FOUCAULT, 1996).

A desmeditização da comunicação faz com que jornalistas, "esses antigos representantes elitistas, esses 'fazedores de opinião' e mesmo sacerdotes da opinião, pareçam completamente superficiais e anacrônicos. A mídia digital dissolve toda classe sacerdotal [...]" (HAN, 2018, p. 37, grifos do autor). Dessa forma, o que antes, na cultura de massa, era mediatizado (por um seleto grupo que detinha o poder de enunciar) e julgado como valor de verdade (pelo grupo agonístico do "nós contra eles"), hoje, na cultura digital - em que todos (nós e eles) podem produzir e postar informação sobre qualquer assunto, a qualquer hora - 
as informações disponíveis nas redes sociais são pré-julgadas como potencial valor de inverdade. Hoje, tudo que está na rede pode ser questionado, mesmo que tenha comprovação científica.

A infodemia e o aumento da divulgação de fake news são consequência direta do processo de desmediatização. Diversos coletivos identitários começaram a publicar nas redes sociais suas próprias representações da realidade, e as fake news emergiram justamente nesse contexto de crise na confiança da veracidade das informações na esfera digital. Quanto mais pessoas se veem autorizadas a produzir e publicar informação, mais informação é gerada e consumida, e, assim, a confiança nas fontes mediatizadas se vê abalada.

A desmediatização também proporcionou o acesso massivo a programas de edição de texto, vídeos e imagens de forma gratuita. Isso significa que toda informação disponível hoje nas redes pode ser alterada, manipulada e editada por programas simples de edição disponíveis a qualquer homo digitalis (HAN, 2018), o que implica em maior desconfiança sobre aquilo a que temos acesso. A desmediatização consiste em uma ação estratégia da política neoliberal vigente que busca o empreendorismo e o autoempresariamento, o endividamento e a despolitização para manter uma reserva de capital humano que aceite o processo de "uberização" de si sem nenhum confronto.

Como indivíduos flexíveis, empreendedores e resilientes, somos demandados a produzir e consumir informação, causa direta da infodemia. Por isso, a sociedade do desempenho (HAN, 2017a) neoliberal se apropriou do fenômeno da infodemia como estímulo ao consumo de informação - e como estratégia persuasiva de acesso ao poder (afinal, conhecimento é poder). Eis a raiz contemporânea do individualismo, cujo horizonte ético- 
político-enunciativo é impelido, pela lógica da hiperprodução de informações, a criar e divulgar narrativas falsas, ou seja, produzir e consumir fake news.

A infodemia expõe esta questão: o hiperconsumo e a hiperprodução de informação geram precisamente (e necessariamente) a falta de verdade. Han (2017b) explica que mais informações, ou o acúmulo de informações, por si sós, não produzem qualquer verdade, e que hiperinformação e hipercomunicação, além de não afastarem a fundamental falta de precisão da informação, intensificam mais ainda essa falta de verdade. A disseminação de fake news como consequência da desmediatização e da infodemia se dá, então, como já problematizei nas seções anteriores, a partir de uma dimensão ideológica de forças pulsionais que mobilizam paixões e crenças, criam mitos e fantasias, apoiadas em uma moralidade forjada na narrativa antitética do "nós/eles".

O ponto de reflexão aqui seria a ideia de que liberdade de informação (acesso e produção) se horizontaliza com transparência (como veracidade). Han, em seu ensaio sobre a sociedade da transparência (2017b), reflete sobre a possibilidade de haver transparência na linguagem. Segundo o filósofo, a transparência nos enunciados é até possível, porém eles seriam formais, operacionais e puramente mecânicos como forma de eliminar toda ambivalência tácita da linguagem. Para Han, é justamente a falta de transparência do outro (do "eles") que mantém viva a relação agonística tanto no contexto real quanto no virtual.

Em se tratando do contexto virtual, a quantidade de fake news nestes últimos anos fez a geopolítica do poder sofrer um enorme impacto. Vimos novas formas de poder disruptivo serem 
alavancadas para o cenário hegemônico pela força das fake news divulgadas aos milhares nas redes sociais. Tal acontecimento gerou um contrafluxo interessante: a sociedade demandou um novo processo de mediatização, no qual os donos das redes sociais - os novos líderes da Era Digital - deveriam se responsabilizar pelo controle e pela mediatização das notícias que são divulgadas em seus domínios virtuais.

Em julho de 2020, em plena pandemia de covid-19, deputados federais se reuniram por videoconferência ${ }^{17}$ para discutir a proposta de combater a desinformação na internet (PL 2630/20). No debate, não houve consenso sobre a criação de normas para divulgação de informações nas redes sociais, mesmo com o enorme impacto negativo que as fake news proporcionaram ao processo eleitoral de 2018. Os deputados tinham de arbitrar sobre normas de autorregulação impostas às plataformas digitais que melhorariam o sistema de curadoria das informações falsas. $\mathrm{O}$ contra-argumento às normas feito por um grupo de deputados se delineou em torno de uma possível censura que tal autorregulação das plataformas poderia impor a seus usuários.

Imagem 2 - Proposta para combater desinformação na internet da Câmara dos Deputados Federais ${ }^{18}$

\section{Responsabilização de redes sociais sobre divulgação de fake news divide opiniões}

Especialistas concordam que desinformação vem afetando processo eleitoral, mas divergem sobre criação de normas legais para plataformas e instituição de conselho para formular código de conduta nas redes sociais

Fonte: Agência Câmara de Notícias 
A criação de um Conselho de Transparência e Responsabilidade na Internet pelo Congresso também foi criticada, uma vez que foi comparado a um "grande irmão", em alusão ao livro 1984, ${ }^{19}$ de George Orwell. Para alguns debatedores, o conselho poderia atuar como sensor ideológico e, assim, levar à criminalização de jornalistas, políticos e ativistas dos direitos humanos. Aqui, temos claramente um embate em torno da narrativa de moralidade, uma fraqueza muito importante da posição pós-política (MOUFFE, 2015), já que a estratégia do antagonismo "amigo/inimigo" não parece ser a mais adequada em se tratando de regulação de divulgação de notícias falsas.

Quase um ano depois desse debate, o processo de mediatização ganhou mais força. Em junho de 2021, partidos de centro-direita cooptaram nuances de uma narrativa de moralidade para apresentar o texto da reforma eleitoral de 2022, que prevê uma espécie de salvo-conduto para candidatos e partidos que divulgam fake news (ou algum conteúdo que viola as regras das plataformas em ano eleitoral) nos meios digitais. Líderes da câmara dos deputados querem estabelecer que as plataformas de internet só podem remover conteúdos publicados em perfis políticos e coligações ou com base em medida judicial, ou a partir da notificação dos responsáveis 24 horas antes da remoção do conteúdo. Se tais medidas forem aprovadas, estaremos diante de legitimação de postagens de fake news num processo de contramediatização oficial.

\footnotetext{
19 Em sua obra distópica, Orwell cria a Novilíngua, uma espécie de léxico sintético e reduzido que visa, entre outras forças de regulação política, reduzir a capacidade de pensar; e o Ministério da Verdade, no qual os funcionários corrigem os testemunhos do passado e reescrevem a história, a fim de que ela se encaixe perfeitamente no discurso legítimo e oficial (Cf. ORWELL, 2003).
} 


\section{Imagem 3 - Discussão parlamente sobre a reforma eleitoral} de 2022

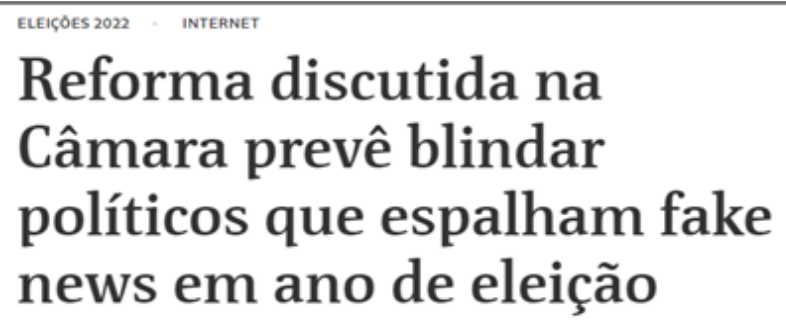

Semelhante a decreto de Bolsonaro, texto proíbe plataformas de removerem perfis de candidatos e exige ordem judicial para derrubar posts

Fonte: Folha de S.Paulo ${ }^{20}$

Pode-se dizer, assim, que essa contramediatização é um efeito gerado pela infodemia como uma espécie de regulação da regulação. Se antes da cultura digital as informações eram dirigidas e filtradas por meio de mediadores, atualmente as instâncias intermediárias interventoras estão cada vez mais dissolvidas e com menos poder de intervenção. Na infodemia, mediação e representação não são mais interpretadas como transparência e eficiência, como luta contra as fake news, e, sim, como congestionamento de tempo e de informação, bem como estratégia política. Essa mudança hoje é normativa "na medida em que ela dita o que é e o que deve ser. Ela define um novo ser [...]" (HAN, 2018, p. 42).

\section{Considerações finais}

Se quisermos lidar realmente com a grave questão da divulgação de fake news, devemos compreender que 
sempre haverá uma dimensão antagonística conflituosa na política democrática. Como bem postulou Mouffe (2015), a especificidade da política não está na superação da oposição "nós/ eles", pois ela é irremediável e estrutura a dimensão políticoeconômica. A especificidade da política na cultura digital está na criação de formas diferentes e de novos paradigmas ainda não estabelecidos nem imaginados. Hoje, a democracia exige não o consenso universal, imaginário e não exequível; exige uma nova formulação da dicotomia "amigo/inimigo" que seja compatível com a aceitação do pluralismo constitutivo da democracia moderna (MOUFFE, 2015).

Assim, concordo com Mouffe (2015) quando ela diz que somente reconhecendo a dimensão antagonística é que podemos avançar na discussão sobre aceitação e legitimação de pluralidades adversárias hegemônicas. Essa possibilidade de aceitação é o que Mouffe (2015) chama de agonismo, ou seja, um terceiro espaço, um tipo de relação no qual os oponentes considerem as pretensões políticas uns dos outros como legítima de modo que todos partilhem o mesmo espaço simbólico de conflitos não entre inimigo, mas, sim, entre adversários.

As fake news, que se inserem como estratégias de manutenção da dimensão antagonística "amigos/imigos", seriam combatidas por uma mediatização advinda de todas as esferas adversárias, de modo que as vozes discordantes se manifestem e se impliquem na luta por uma reconfiguração das relações de poder. Tais reconfigurações seriam reguladas por um conjunto de procedimentos democráticos aceitos pelos adversários (MOUFFE, 2015, p. 20), em uma ordem hegemônica multipolar, na qual o pluralismo seja realmente levado a sério. 
Referências

BAKHTIN. M. Estética da criação verbal. 6. ed. São Paulo: Martins Fontes, 2011.

DEPUTADOS e especialistas sugerem novas formas de combate às fake news - 22/07/20. Brasília: Câmara dos Deputados, 22 jul. 2020. 1 vídeo (4m48s). Publicado por Câmara dos Deputados. Disponível em: https://www.youtube.com/ watch $\mathrm{v}=\mathrm{N} 8 \mathrm{CSnMakeyM} \& \mathrm{ab} \_$channel $=\mathrm{C} \% \mathrm{C} 3 \% \mathrm{~A} 2$ maradosD eputados. Acesso em: 25 jun. 2021.

DUSSEL. E. 20 Teses de Política. São Paulo: Expresso Popular, 2007.

FOUCAULT. M. A ordem do discurso. 3. ed. São Paulo, Edições Loyola, 1996.

FOUCAULT. M. A sociedade punitiva. São Paulo: Martins Fontes, 2015.

FOUCAULT. M. Microfísica do poder. 26. ed. Rio de Janeiro: Edições Graal, 2008.

GOULART, Nathalia. As lições do livro que desensina: 'Por Uma Vida Melhor' é exemplo de doutrina difundida há décadas na educação brasileira, segundo a qual a norma culta é um fardo ao qual devemos nos curvar por imposição social, e não pelos benefícios que ela propicia. Veja, [S. l.], 20 mai. 2011. Disponível em: https://veja.abril.com.br/educacao/as-licoes-dolivro-que-desensina. Acesso em: 9 jun. 2021.

HAJE, Lara. Responsabilização de redes sociais sobre divulgação de fake news divide opiniões. Agência Câmara de Notícias, Brasília, 22 jul. 2020. Ciência, Tecnologia e Comunicações. Disponível em: https://www.camara.leg.br/noticias/678465responsabilizacao-de-redes-sociais-sobre-divulgacao-de-fakenews-divide-opinioes/. Acesso em: 25 jun. 2021. 
HAN. B. No enxame: perspectivas do digital. Petrópolis-RJ: Vozes, 2018.

HAN. B. Sociedade da transparência. Petrópolis-RJ: Vozes, $2017 \mathrm{~b}$.

HAN. B. Sociedade do cansaço. Petrópolis-RJ: Vozes, 2017a.

HARARI. Y. N. Sapiens: uma breve história da humanidade. 26. ed. Porto Alegre: L\&M, 2017.

HEGEL, G.W.F. Fenomenologia do Espírito. Tradução de Paulo Menezes. 2. ed. Petrópolis: Vozes, 2002.

KANT. I. Crítica da razão pura. 5. ed. Lisboa: Fundação Calouste Gulbenkian, 2001.

LACAN, J. Nomes-do-Pai. Rio de Janeiro: Jorge Zahar, 2005.

LACAN, Jacques. O estádio do espelho como formador da função do eu. In: LACAN, Jacques. Escritos. Rio de Janeiro: Jorge Zahar, 1998. p. 96-103.

MARX, K.; ENGELS, F. A ideologia alemã. São Paulo: Martins Fontes, 2007

MELLO, Patrícia Campos. Reforma discutida na Câmara prevê blindar políticos que espalham fake news em ano de eleição. Folha de S. Paulo, São Paulo, 23 jun. 2021. Eleições 2022 Internet. Disponível em: https://www1.folha.uol.com. br/poder/2021/06/reforma-discutida-na-camara-preve-blindarpoliticos-que-espalham-fake-news-em-ano-de-eleicao shtml. Acesso em: 6 jun. 2021.

MOUFFE. C. Sobre o político. São Paulo: Martins Fontes, 2015. ORGANIZAÇÃO PAN-AMERICANA DA SAÚDE. Entenda a infodemia e a desinformação na luta contra a COVID-19. Página informativa n. 5, 5p. 2020. Disponível em: https:// iris.paho.org/bitstream/handle/10665.2/52054/FactsheetInfodemic_por.pdf?sequence=14. Acesso em 10 jun. 2021. 
ORWELL, George. 1984. 29. ed. São Paulo: Companhia Editora Nacional, 2003. 301 p.

PEREZ, D. O. O populismo, a massa e a afetividade. CONJECTURA: filosofia e educação, v. 23, n. Especial, p. 171-196, 2018.

POR UMA VIDA Melhor. Fala de Alexandre Garcia no Bom Dia Brasil, sobre o livro que ensina português errado. [S.l.]: 2012Lucinha. 1 vídeo. (1m05s). 20 mai. 2011. Disponível em: https://www.youtube.com/watch?v=w_uZc-99plI\&ab_ channel=2012Lucinha. Acesso em: 10 jun. 2021.

PROCESSO contra livro do MEC com erros de concordância é arquivado. G1.Globo.com, São Paulo, 1. jul. 2011. Educação. Disponível em: http://g1.globo.com/educacao/noticia/2011/07/ processo-contra-livro-do-mec-com-erros-de-concordancia-earquivado.html. Acesso em: 10 jun. 2021.

SADENBERG, Carlos Alberto. Se pelo menos ensinassem português. O Estado de S. Paulo, São Paulo, 16 mai. 2011. Economia. Disponível em: https://economia.estadao.com. br/noticias/geral,se-pelo-menos-ensinassem-portuguesimp-,719641. Acesso em: 9 jun. 2021.

SCHMITT, C. The Concept of the Political. New Brunswick, Rutgers University Press, 1976.

ZAROCOSTAS, J. How to fight an infodemic. The Lancet, v. 395, n. 10225, 2020. 